\title{
Situación actual de la especialidad de psicología clínica
}

La Orden Ministerial, que establece los procedimientos de aplicación de las disposiciones transitorias del Decreto de la Especialidad en Psicología Clínica, entró en el periodo de tramitación en el mes de marzo. Como ya hemos informado anteriormente, el Ministerio se comprometió a agilizar el procedimiento de forma que la Orden pudiera estar publicada en el Boletín Oficial en septiembre. En estos momentos se ha terminado el periodo de consultas a las Comunidades Autónomas, de forma que una vez tramitadas en la Secretaria General Técnica, se abrirá el periodo de audiencia publica que según nos comunican será de 15 días. Las alegaciones de las CCAA son, al parecer, meramente formales, por lo que no hay ningún problema para que el proceso siga adelante. A pesar de todo ello nos parece evidente la lentitud con la que se esta gestionando todo el proceso.

Por otro lado la Comisión Nacional de la Especialidad solicitó, a raíz de su constitución oficial, su inclusión en el Consejo Nacional de Especialidades Médicas, como el resto de las especialidades. La respuesta ha sido negativa con el argumento de que la Psicología Clínica no es una especialidad médica. La misma respuesta ha recibido la Comisión Nacional de Radiofísicos. La respuesta nos parece cuanto menos incongruente, ya que deja a la especialidad de Psicología Clínica en una situación totalmente ambigua, sin formar parte del organigrama institucional del Ministerio, a pesar de ser una especialidad sanitaria oficialmente reconocida.

La situación planteada, tanto por la lentitud en la tramitación de la orden como por la negativa a la Comisión de formar parte del Consejo Nacional de Especialidades Medicas, nos parece sumamente delicada y grave. El hecho de que hayan transcurrido dos años desde la promulgación del Decreto de la Especialidad sin que de facto se pueda poner en practica, es decir, no se pueda homologar a los profesionales que están desarrollando sus actividades en los servicios sanitarios públicos, deja a todo el colectivo cientifico-profesional en una situación de extrema precariedad y evidente injusticia. Los compañeros del Insalud están esperando ser reconocidos como especialistas para ser retribuidos como el resto de los psicólogos, mientras desarrollan exactamente las mismas funciones. Otros están a la espera de poderse presentar a oposiciones como facultativos, etc. A esto hay que añadir la ambigüedad del Ministerio de Sanidad que, por un lado reconoce a la Psicología Clínica como especialidad sanitaria, al tiempo que no le concede un lugar institucional en el organigrama ministerial, resultando por tanto que no tiene voz ni voto para plantear las 
cuestiones estructurales relacionadas con su ámbito de actuación (programa de formación de especialistas, áreas de capacitación especifica, problemas de competencias, etc.)

Por todo ello desde la AEN nos dirigiremos al Ministerio de Sanidad para instar a la rápida tramitación de la Orden y a la clarificación de la situación institucional de la Comisión Nacional. 